\title{
Modified Gauss-Newton Algorithm for Evaluation of Full Lightning Impulse Voltage Parameters
}

\author{
Panuwat Jamroen, Poom Yoosorn, \\ Suthasinee Waengsothorn, and Peerawut Yutthagowith* \\ School of Engineering, King Mongkut's Institute of Technology Ladkrabang, \\ 1 Soi Chalongkrung 1, Ladkrabang, Bangkok 10520, Thailand
}

(Received January 29, 2021; accepted June 16, 2021)

Keywords: curve fitting technique, Gauss-Newton method, Levenberg-Marquardt algorithm, lightning impulse voltage, two-exponential function

This paper presents an efficient curve fitting technique based on a Gauss-Newton (GN) method with a varied damping factor for the evaluation of lightning impulse voltage parameters. The proposed method can be used to determine the base curves of full lightning impulse voltages with oscillations corrected from the parameters of test cases according to the standard (IEC 61083-2). To verify the performance of the proposed method, base curves reconstructed from the developed method were compared with curves reconstructed from nonlinear least squares regression using the Levenberg-Marquardt (LM) algorithm, as prescribed in the standard. The proposed method provides the same results as the standard recommended method but its execution time is significantly shorter. The results of this study indicate that the proposed method is suitable for evaluating lightning impulse voltage parameters.

\section{Introduction}

Lightning overvoltage is a major cause of insulation failures of high-voltage equipment installed in high-voltage transmission and distribution systems. Therefore, it is necessary to perform lightning impulse voltage tests on high-voltage equipment to confirm its insulation performance. The lightning impulse voltage generated in a testing laboratory must have the waveform parameters required in the standard. ${ }^{(1,2)}$

A test object with a complicated structure under an impulse voltage test sometimes cannot be represented well by simple lumped circuit elements. Also, some parasitic circuit components in a real circuit, i.e., parasitic capacitance and inductance, lead to voltage waveforms with some oscillation and overshoot. ${ }^{(3-12)}$ Therefore, it is necessary that a standard approach is defined for evaluating lightning impulse voltage waveform parameters. ${ }^{(1,2)}$ The standard approach is based on determining the base curve and $k$-factor filtering to reduce the unwanted noise signal. By using digital waveform data and software for parameter evaluation, the standard (IEC 61083-2) (13) $^{(13)}$ provides a software program named Test Data Generation (TDG) for the generation of

*Corresponding author: e-mail: peerawut.yu@kmitl.ac.th https://doi.org/10.18494/SAM.2021.3309 
waveforms, which are utilized to test the software for evaluating the impulse waveform parameters. In addition, the standard recommends nonlinear regression [Levenberg-Marquardt (LM) algorithm] to determine the base curve to evaluate the waveform parameters. However, nonlinear regression sometimes has low efficiency for a waveform with a high overshoot rate. This has motivated researchers to develop algorithms to increase the efficiency of nonlinear regression and also special linear regression algorithms for evaluating waveform parameters. $^{(14-16)}$

In this paper, a Gauss-Newton (GN) method with a varied damping factor is proposed for evaluating the base curve of a full wave lightning impulse voltage. A comparison of the performance of the proposed method and the standard recommended method is presented. The proposed method shows reasonably high accuracy and noise immunity comparable to those of the standard recommended method but has a shorter computation time due to the lower complexity of the calculation.

\section{Proposed Curve Fitting Method}

For a better understanding of the proposed method, the waveforms in Fig. 1 are presented. According to the standard, the lightning impulse voltage waveform parameters can be evaluated by the following procedures.

(1) Collect the waveform from $20 \%$ of the peak voltage in the front part to $40 \%$ of the peak voltage in the tail part. This collected waveform is called the recorded waveform.

(2) Fit the recorded waveform with the function in Eq. (1). The coefficients of the function, i.e., $\alpha, \beta, A$, and $t_{d}$, are computed, and the waveform with these coefficients is called the base curve.

$$
g(t)=A\left(e^{-\alpha\left(t-t_{d}\right)}-e^{-\beta\left(t-t_{d}\right)}\right)
$$

(3) Subtract the base curve from the recorded curve. The obtained result is the residual curve. Then, the residual curve is filtered by the $k$-factor filter, whose equation is expressed by

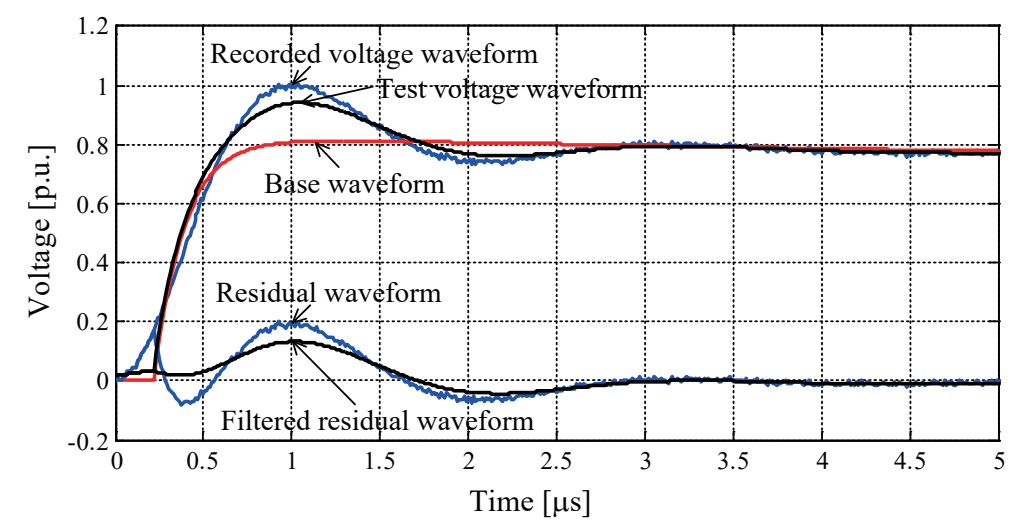

Fig. 1. (Color online) Process used to evaluate impulse voltage and current waveforms. 


$$
k(f)=\frac{1}{\left(1+2.2 f^{2}\right)},
$$

where $f$ is the frequency in MHz.

Lewin et al. ${ }^{(17)}$ proposed an approach to implement the filter in the frequency domain in the form of a zero-phase-shift infinite impulse response (IIR) filter. The filtered waveform is called the filtered residual curve.

(4) Add the filtered residual curve to the base curve. The resulting waveform is called the test voltage curve. The waveform parameters, i.e., the front time $\left(T_{1}\right)$, the time to half $\left(T_{2}\right)$, the peak voltage $\left(U_{p}\right)$, and the overshoot rate $\left(\beta_{e}\right)$, are evaluated as percentages from the test voltage curve.

In this paper, a GN method with varied damping factors for obtaining a base curve is proposed as follows. Firstly, the recorded waveform is collected from $20 \%$ of the peak voltage in the front part to $40 \%$ of the peak voltage in the tail part. The time scale of this collected waveform is moved to start at zero. Then, the waveform is normalized with the offset level and the peak voltage. ${ }^{(15,16)}$ The fitting function recommended by the standard method can be rearranged into the following simplified form:

$$
f(t)=A e^{-\alpha t}+B e^{-\beta t} .
$$

Then, the four remaining parameters, $A, B, \alpha$, and $\beta$, are estimated.

The GN method is a type of nonlinear regression or nonlinear curve fitting. For the sake of understanding, let us consider the square error function $[e(A, B, \alpha, \beta)]$ defined as

$$
e(A, B, \alpha, \beta)=\sum_{i=1}^{n}(y(i)-g(i, A, B, \alpha, \beta))^{2},
$$

where $y(i)$ is the value of the recorded waveform at point $i$.

The error function is minimized by the GN method to obtain the values of $A, B, \alpha$, and $\beta$. The GN method starts from the approximation of $G(X)$ expressed as

$$
G(X+\Delta X) \approx G(X)+J \Delta X,
$$

where

$$
X=[A B \alpha \beta]^{t},
$$

$$
\Delta X=[\Delta A \Delta B \Delta \alpha \Delta \beta]^{t},
$$




$$
\begin{gathered}
G(X)=[g(1, X) g(2, X) g(3, X) \ldots g(n, X)]^{t}, \\
J=\left[\begin{array}{cccc}
\frac{\partial g(1, X)}{\partial A} & \frac{\partial g(1, X)}{\partial B} & \frac{\partial g(1, X)}{\partial \alpha} & \frac{\partial g(1, X)}{\partial \beta} \\
\frac{\partial g(2, X)}{\partial A} & \frac{\partial g(2, X)}{\partial B} & \frac{\partial g(2, X)}{\partial \alpha} & \frac{\partial g(2, X)}{\partial \beta} \\
\frac{\partial g(3, X)}{\partial A} & \frac{\partial g(3, X)}{\partial B} & \frac{\partial g(3, X)}{\partial \alpha} & \frac{\partial g(3, X)}{\partial \beta} \\
\vdots & \vdots & \vdots & \vdots \\
\frac{\partial g(n, X)}{\partial A} & \frac{\partial g(n, X)}{\partial B} & \frac{\partial g(n, X)}{\partial \alpha} & \frac{\partial g(n, X)}{\partial \beta}
\end{array}\right] .
\end{gathered}
$$

Equation (5) can be rewritten as Eq. (10). Assuming that $G(X+\Delta X)=Y$ and applying linear regression to Eq. (10), we obtain $\Delta X$ as

$$
\begin{gathered}
E(X+\Delta X)=G(X+\Delta X)-G(X)=J \Delta X \\
\Delta X=\left(J^{t} J\right)^{-1} J^{t} E(X+\Delta X) .
\end{gathered}
$$

To obtain the minimum value of the error function, $X$ is updated to $X+\Delta X$ and is calculated iteratively until the relative error $\left(\varepsilon_{i}\right)$ is less than the tolerance limit defined by Eq. (12). In this paper, the tolerance limit is set to $10^{-6} . \varepsilon_{i}$ is given by

$$
\varepsilon_{i}=\frac{\left\|e(A, B, \alpha, \beta)_{i}-e(A, B, \alpha, \beta)_{i-1}\right\|}{\left\|e(A, B, \alpha, \beta)_{i-1}\right\|}
$$

where $\varepsilon_{i}$ is the relative error at the $i$ th iteration. The maximum number of iterations in the curve fitting method is set to 200 .

It has been found that when the conventional GN method is applied to evaluate the waveform parameters using the standard waveforms, ${ }^{(13)}$ the solution of $X$ sometimes cannot reach the set tolerance limit. To solve this problem, the updated value of $X$ is set to

$$
X_{k+1}=X_{k}+d \Delta X_{k},
$$

where $X_{k+1}$ is the updated value of $X$ at the $k$ th iteration and $d$ is the damping factor.

\section{Performance of Proposed Method}

In this section, 29 standard waveforms taken from the standard ${ }^{(13)}$ are used in parameter evaluation. The time step and the resolution of all waveforms were set to $10 \mathrm{~ns}$ and 12 bits, 
respectively. The standard recommended and proposed methods were applied to evaluate the waveform parameters. In the proposed method, the damping factor $(d)$ is considered. It is found that the GN method with fixed $d$ (first option) and with $d$ varied during the iteration (second option) can obtain the same waveform parameters as the standard recommended method (LM). The waveform parameters are presented in Fig. 2.

Test Voltage

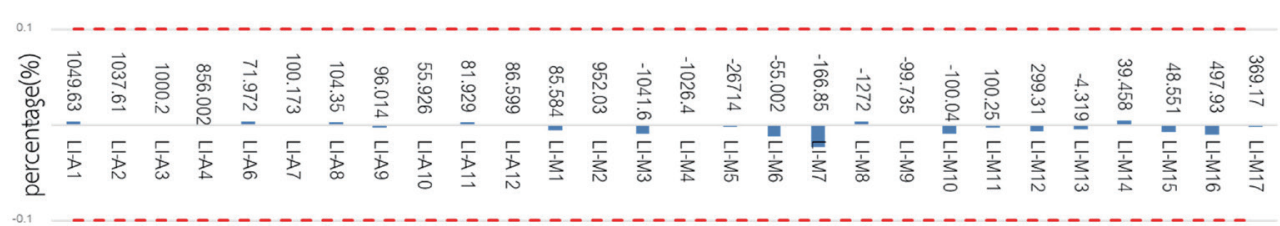

(a)

Front Time

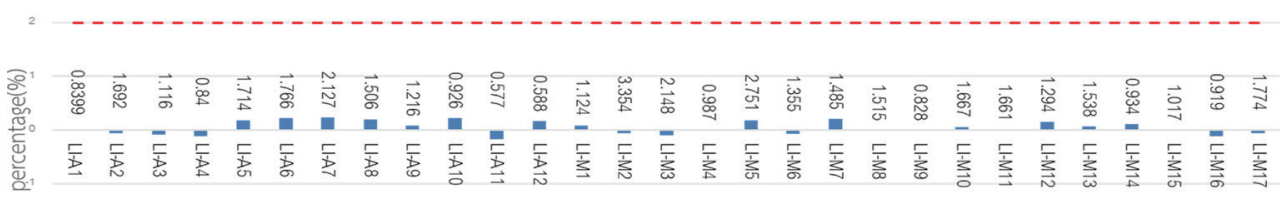

(b)

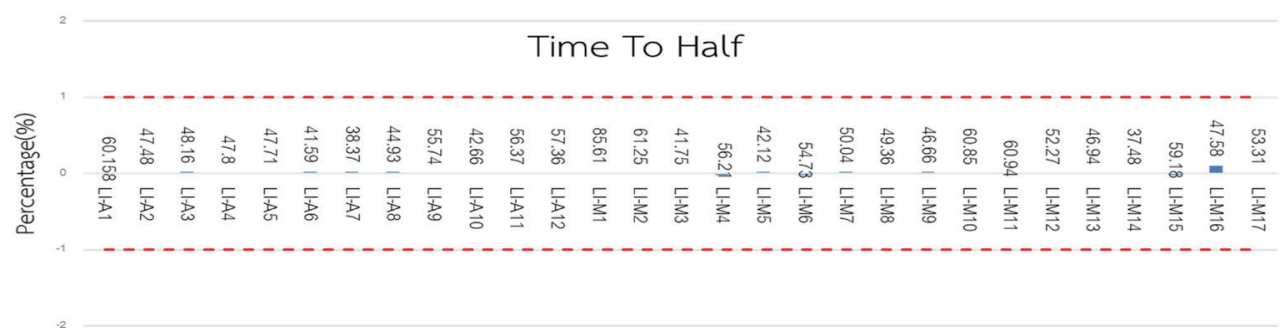

(c)

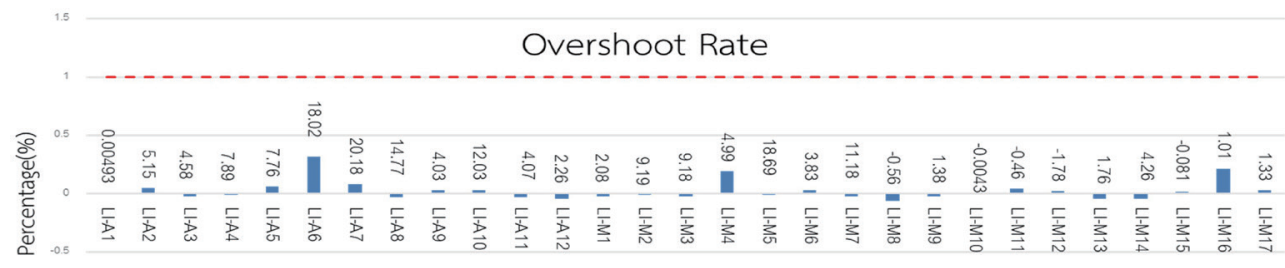

(d)

Fig. 2. (Color online) Waveform parameters evaluated by the proposed method and the standard recommended method in comparison with the standard tolerances. (a) test voltage, (b) front time, (c) time to half, and (d) overshoot rate. 
In the first option, the optimal value of the constant damping factor is found by testing with $d$ varied from 0.5 to 1.2 . When $d>1.0$, the GN method cannot reach the optimum solution after 200 iterations in some test cases, making it unsuitable for waveform parameter evaluation. In contrast, the GN method with $d<1.0$ can find the optimum solution in all test cases. However, when $d<0.8$, a large number of iterations (a few tens of iterations) and a long execution time are required to obtain the parameters by the GN method. The GN method with $d=0.8$ provides the best performance in terms of the execution time and the number of iterations.

On the basis of the results for the first option of the damping factor, we decided to vary the damping factor during the iteration process (second option). $d$ is set to 1 for the first and second iterations and to 0.8 for the other iterations. The parameters of the normalized base waveforms calculated by the LM and GN methods are the same, as shown in Table 1. It was found that the performance of this proposed method in terms of the execution time is superior to that of the GN method with a constant damping factor, as can be seen from Table 2. The GN method with the varied damping factor can find the optimum solution and the waveform parameters in all test cases. The average number of iterations and the execution time of the GN method with the varied

Table 1

Parameters of the base waveforms computed by the GN and LM methods.

\begin{tabular}{|c|c|c|c|c|}
\hline Case & $\mathrm{A}$ & B & $\alpha$ & $\beta$ \\
\hline LI-A1 & 1.044 & -0.817 & $1.193 \mathrm{E} 4$ & $3.614 \mathrm{E} 6$ \\
\hline LI-A2 & 0.998 & -0.826 & $1.476 \mathrm{E} 4$ & $1.932 \mathrm{E} 6$ \\
\hline LI-A3 & 0.978 & -0.905 & $1.475 \mathrm{E} 4$ & 2.523E6 \\
\hline LI-A4 & 0.928 & -0.867 & $1.377 \mathrm{E} 4$ & $4.034 \mathrm{E} 6$ \\
\hline LI-A5 & 0.968 & -0.900 & $1.406 \mathrm{E} 4$ & $1.985 \mathrm{E} 6$ \\
\hline LI-A6 & 0.865 & -0.809 & $1.336 \mathrm{E} 4$ & $2.576 \mathrm{E} 6$ \\
\hline LI-A7 & 0.844 & -0.785 & $1.377 \mathrm{E} 4$ & $2.295 \mathrm{E} 6$ \\
\hline LI-A8 & 0.884 & -0.827 & $1.307 \mathrm{E} 4$ & 2.689E6 \\
\hline LI-A9 & 0.989 & -0.899 & $1.240 \mathrm{E} 4$ & $2.568 \mathrm{E} 6$ \\
\hline LI-A10 & 0.888 & -0.847 & $1.463 \mathrm{E} 4$ & $4.008 \mathrm{E} 6$ \\
\hline LI-A11 & 0.986 & -0.874 & $1.216 \mathrm{E} 4$ & $5.433 \mathrm{E} 6$ \\
\hline LI-A12 & 1.002 & -0.902 & $1.213 \mathrm{E} 4$ & $5.208 \mathrm{E} 6$ \\
\hline LI-M1 & 0.998 & -0.784 & $8.263 \mathrm{E} 3$ & $2.660 \mathrm{E} 6$ \\
\hline LI-M2 & 0.950 & -0.770 & $1.134 \mathrm{E} 4$ & $1.041 \mathrm{E} 6$ \\
\hline LI-M3 & 0.964 & -0.786 & 1.709E4 & $1.559 \mathrm{E} 6$ \\
\hline LI-M4 & 0.975 & -0.848 & $1.203 \mathrm{E} 4$ & $3.005 \mathrm{E} 6$ \\
\hline LI-M5 & 0.870 & -0.774 & $1.284 \mathrm{E} 4$ & $1.689 \mathrm{E} 6$ \\
\hline LI-M6 & 1.008 & -0.830 & $1.300 \mathrm{E} 4$ & $2.192 \mathrm{E} 6$ \\
\hline LI-M7 & 0.932 & -0.902 & $1.268 \mathrm{E} 4$ & 2.308E6 \\
\hline LI-M8 & 1.055 & -0.883 & $1.522 \mathrm{E} 4$ & $1.926 \mathrm{E} 6$ \\
\hline LI-M9 & 1.022 & -0.893 & $1.532 \mathrm{E} 4$ & $3.572 \mathrm{E} 6$ \\
\hline LI-M10 & 1.051 & -0.670 & $1.234 \mathrm{E} 4$ & $1.572 \mathrm{E} 6$ \\
\hline LI-M11 & 1.059 & -0.830 & $1.229 \mathrm{E} 4$ & $1.702 \mathrm{E} 6$ \\
\hline LI-M12 & 1.067 & -0.860 & $1.454 \mathrm{E} 4$ & $2.142 \mathrm{E} 6$ \\
\hline LI-M13 & 1.027 & -0.874 & $1.554 \mathrm{E} 4$ & $1.948 \mathrm{E} 6$ \\
\hline LI-M14 & 1.003 & -0.894 & $1.880 \mathrm{E} 4$ & 3.324E6 \\
\hline LI-M15 & 1.032 & -0.924 & $1.232 \mathrm{E} 4$ & $2.802 \mathrm{E} 6$ \\
\hline LI-M16 & 1.044 & -0.823 & $1.524 \mathrm{E} 4$ & $3.217 \mathrm{E} 6$ \\
\hline LI-M17 & 1.038 & -0.704 & $1.415 \mathrm{E} 4$ & $1.572 \mathrm{E} 6$ \\
\hline
\end{tabular}


Table 2

Comparison of performance of the standard recommended and proposed methods.

\begin{tabular}{|c|c|c|c|c|c|c|c|c|}
\hline \multirow[b]{2}{*}{ Case } & \multicolumn{2}{|c|}{ LM } & \multicolumn{2}{|c|}{$\mathrm{GN}(d=1.0)$} & \multicolumn{2}{|c|}{$\mathrm{GN}(d=0.8)$} & \multicolumn{2}{|c|}{ GN (varied $d$ ) } \\
\hline & $\begin{array}{l}\text { Number of } \\
\text { iterations }\end{array}$ & $\begin{array}{l}\text { Execution } \\
\text { time (s) }\end{array}$ & $\begin{array}{l}\text { Number of } \\
\text { iterations }\end{array}$ & $\begin{array}{l}\text { Execution } \\
\text { time (s) }\end{array}$ & $\begin{array}{c}\text { Number of } \\
\text { iterations }\end{array}$ & $\begin{array}{l}\text { Execution } \\
\text { time (s) }\end{array}$ & $\begin{array}{c}\text { Number of } \\
\text { iterations }\end{array}$ & $\begin{array}{l}\text { Execution } \\
\text { time (s) }\end{array}$ \\
\hline LI-A1 & 5 & 0.02126 & 4 & 0.01073 & 7 & 0.01474 & 6 & 0.01396 \\
\hline LI-A2 & 6 & 0.03636 & 6 & 0.00927 & 6 & 0.00605 & 4 & 0.01119 \\
\hline LI-A3 & 4 & 0.01136 & 4 & 0.00579 & 6 & 0.01154 & 4 & 0.00952 \\
\hline LI-A4 & 10 & 0.02483 & 9 & 0.01404 & 6 & 0.00863 & 6 & 0.00892 \\
\hline LI-A5 & 10 & 0.02427 & 9 & 0.01515 & 6 & 0.00753 & 6 & 0.01033 \\
\hline LI-A6 & 30 & 0.05532 & 28 & 0.03013 & 6 & 0.02199 & 7 & 0.00744 \\
\hline LI-A7 & 13 & 0.02800 & $200(\mathrm{~F})$ & 0.24233 & 10 & 0.02516 & 13 & 0.01713 \\
\hline LI-A8 & 18 & 0.04165 & 18 & 0.01913 & 6 & 0.01002 & 8 & 0.00933 \\
\hline LI-A9 & 5 & 0.01531 & 5 & 0.01279 & 6 & 0.00823 & 4 & 0.00714 \\
\hline LI-A10 & 13 & 0.02645 & 12 & 0.01728 & 7 & 0.01094 & 7 & 0.00676 \\
\hline LI-A11 & 6 & 0.01568 & 5 & 0.00928 & 7 & 0.01631 & 6 & 0.01289 \\
\hline LI-A12 & 7 & 0.01984 & 6 & 0.01108 & 7 & 0.00975 & 6 & 0.01197 \\
\hline LI-M1 & 6 & 0.02671 & 6 & 0.00966 & 7 & 0.01576 & 7 & 0.01213 \\
\hline LI-M2 & 7 & 0.01996 & 9 & 0.01014 & 7 & 0.00938 & 9 & 0.00810 \\
\hline LI-M3 & 6 & 0.01594 & 6 & 0.00756 & 7 & 0.00770 & 6 & 0.00710 \\
\hline LI-M4 & 4 & 0.00982 & 4 & 0.00441 & 6 & 0.00777 & 4 & 0.00537 \\
\hline LI-M5 & 59 & 0.09794 & 57 & 0.03918 & 11 & 0.01123 & 13 & 0.01508 \\
\hline LI-M6 & 4 & 0.01172 & 4 & 0.00742 & 6 & 0.01417 & 4 & 0.00720 \\
\hline LI-M7 & 12 & 0.02648 & 12 & 0.00809 & 6 & 0.00756 & 7 & 0.00841 \\
\hline LI-M8 & 4 & 0.01318 & 4 & 0.00787 & 6 & 0.00587 & 4 & 0.00795 \\
\hline LI-M9 & 5 & 0.01321 & 5 & 0.00551 & 6 & 0.00469 & 5 & 0.00549 \\
\hline LI-M10 & 4 & 0.00983 & 4 & 0.00996 & 7 & 0.00664 & 5 & 0.01284 \\
\hline LI-M11 & 4 & 0.03606 & 4 & 0.00812 & 7 & 0.01300 & 5 & 0.01332 \\
\hline LI-M12 & 5 & 0.01295 & 4 & 0.01078 & 7 & 0.01061 & 5 & 0.00861 \\
\hline LI-M13 & 6 & 0.01446 & 5 & 0.00742 & 6 & 0.03880 & 5 & 0.00791 \\
\hline LI-M14 & 6 & 0.01186 & 6 & 0.00706 & 7 & 0.00909 & 5 & 0.02297 \\
\hline LI-M15 & 4 & 0.01445 & 4 & 0.00825 & 7 & 0.01108 & 4 & 0.00934 \\
\hline LI-M16 & 5 & 0.01563 & 4 & 0.01062 & 6 & 0.01965 & 5 & 0.00916 \\
\hline LI-M17 & 4 & 0.01160 & 4 & 0.00944 & 8 & 0.01397 & 4 & 0.01488 \\
\hline Average & 9.38 & 0.02352 & 15.45 & 0.01960 & 6.79 & 0.01234 & 6.00 & 0.01043 \\
\hline Max & 59 & 0.09794 & 200 & 0.24233 & 11 & 0.03880 & 13 & 0.02297 \\
\hline Min & 4 & 0.00982 & 4 & 0.00441 & 6 & 0.00469 & 4 & 0.00537 \\
\hline Median & 6 & 0.01594 & 5 & 0.00966 & 7 & 0.01061 & 5 & 0.00933 \\
\hline
\end{tabular}

Note that the GN method with $d=1.0$ failed to determine the optimum solution in case LI-A7.

damping factor are slightly less than those of the GN method with the constant damping factor and the standard recommended method, but the execution time of the proposed method is only half that of the LM algorithm. In addition, the LM algorithm is more complicated than the proposed method, which can be readily implemented as a program for evaluating the lightning waveform parameters.

The performances of the methods in terms of the number of iterations and the execution time are compared in Table 2. Owing to space limitation, only the performances of the cases with $d=1, d=0.8$, and $d=1$ for the first and second iterations and $d=0.8$ thereafter are presented. 
Figures 3-5 illustrate the results for cases LI-A7, LI-M5, and LI-M17, respectively. The blue solid lines, black solid lines, and red dotted lines denote the recorded, test, and base waveforms, respectively.

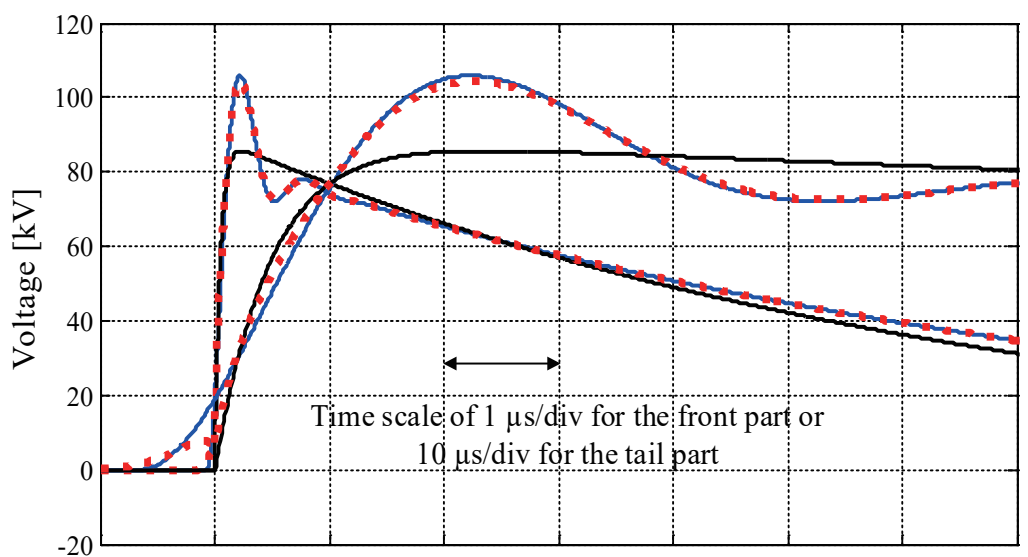

Fig. 3. (Color online) Waveforms evaluated by the proposed method in case LI-A7.

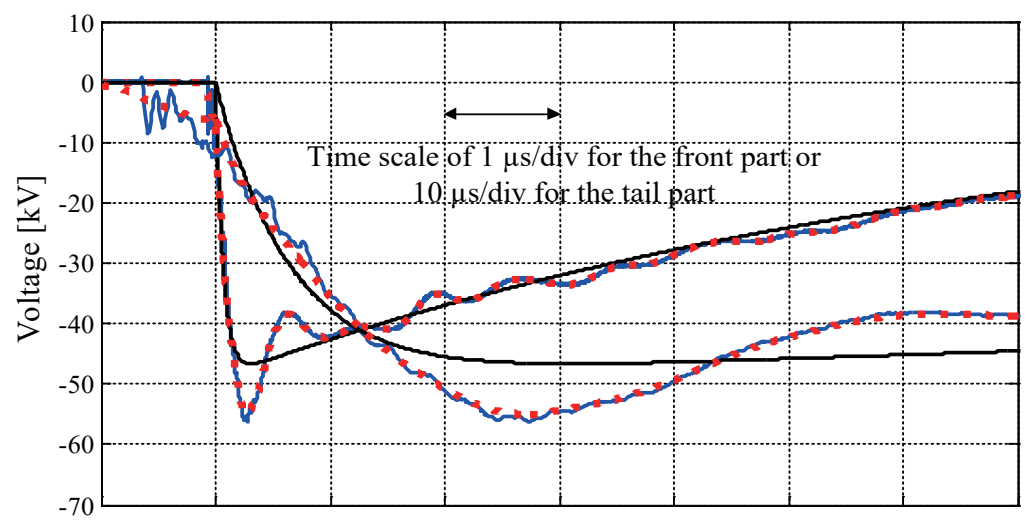

Fig. 4. (Color online) Waveforms evaluated by the proposed method in Case LI-M5.

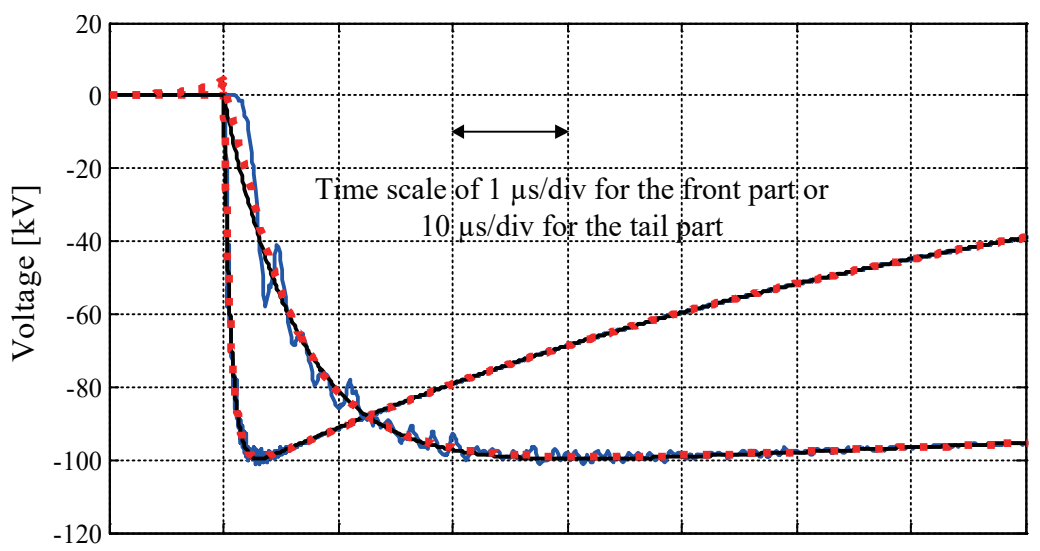

Fig. 5. (Color online) Waveforms evaluated by the proposed method in Case LI-M17. 


\section{Conclusions}

An efficient curve fitting technique based on the GN method with the damping factor varied was proposed for the evaluation of the lightning impulse voltage parameters. The validity of the proposed method was verified using the standard waveforms collected from the test cases according to the standard (IEC 61083-2). The proposed method provides the same results as the standard recommended method (LM algorithm). The performances of the proposed method in terms of the number of iterations and the execution time were investigated in comparison with the standard recommended method. It was found that the number of iterations and the execution time of the proposed method are significantly less than those of the GN method with a constant damping factor and the standard recommended method. Owing to the low complexity of the model, the proposed method is very attractive for the development of software to evaluate the full lightning waveform parameters by test engineers and scientists lacking experience in software development.

\section{Acknowledgments}

The authors would like to give special acknowledgment to the School of Engineering, King Mongkut's Institute of Technology Ladkrabang, for providing the facility in this research work. This project was funded by the National Research Council of Thailand.

\section{References}

1 High-Voltage Test Techniques Part 1- General Definitions and Test Requirements: International Standard IEC 60060-1 (Geneva, Switzerland, 2010) 3rd ed.

2 IEEE Standard Techniques for High-Voltage Testing: IEEE Power and Energy Society, IEEE Standard 4-2013. (New York, USA, 2013).

3 T. Tsuboi, G. Ueta, S. Okabe, Y. Shimizu, T. Ishikura, and E. Hino: IEEE Trans. Power Del. 28 (2013) 1148. https://doi.org/10.1109/TPWRD.2012.2235862

4 F. Garnacho, A. Khamlichi, A. Valladolid, P. Simon, and R. Guirado: IEEE Trans. Power Del. 28 (2013) 686. https://doi.org/10.1109/TPWRD.2012.2228012

5 F. Garnacho, A. Khamlichi, A. Valladolid, P. Simon, and M. Valcarcel: IEEE Trans. Power Del. 29 (2014) 2254. https://doi.org/10.1109/TPWRD.2014.2300137

6 J.-T. Kuan and M.-K.Chen: IEEE Trans. Dielectr. Electr. Insul. 13 (2006) 1303. https://doi.org/10.1109/ TDEI.2006.258202

7 H. Jouybari-Moghaddam, B. Vahidi, and S. H. Hosseinian: IEEE Trans. Power Del. 28 (2013) 531. https://doi. org/10.1109/TPWRD.2012.2213172

8 P. Simon, F. Garnacho, S. M. Berlijn, and E. Gockenbach: IEEE Trans. Power Del. 21 (2006) 560. https://doi. org/10.1109/TPWRD.2012.2213172

9 M. Hinow, W. Hauschild, and E. Gockenbach: IEEE Trans. Dielectr. Electr. Insul. 17 (2010) 1628. https://doi. org/10.1109/TDEI.2010.5595567

10 S. Okabe, T. Tsuboi, G. Ueta, J. Takami, and H. Hirose: IEEE Trans. Dielectr. Electr. Insul. 17 (2010) 2. https:// doi.org/10.1109/TDEI.2010.5411995

11 G. Ueta, T. Tsuboi, and S. Okabe: IEEE Trans. Dielectr. Electr. Insul. 18 (2011) 783. https://doi.org/10.1109/ TDEI.2011.5931066

12 G. Ueta, T. Tsuboi, and S. Okabe: IEEE Trans. Dielectr. Electr. Insul. 19 (2012) 352. https://doi.org/10.1109/ TDEI.2012.6148538

13 Instruments and Softwares Used for Measurement in High-volatge and High-current Tests Part 2: Requirement for Software for Tests with Impulse Voltages and Currents: International Standard IEC 61083-2 (Geneva, Switzerland, 2013) 2nd ed. 
14 E. A. Feilat: IEEE Trans. Power Del. 21 (2006) 2088. https://doi.org/10.1109/TPWRD.2006.881984

15 N. Patanadech and P. Yutthagowith: IEEE Trans. Dielectr. Electr. Insul. 22 (2015) 783. https://doi.org/10.1109/ TDEI.2015.005165

16 P. Yutthagowith and N. Patanadech: IEEE Trans. Power Del. 28 (2013) 531. https://doi.org/110.1109/ TPWRD.2015.2448640

17 P. L. Lewin, T. N. Tran, D. J. Swaffield, and J. K. Hällström: IEEE Trans. Power Del. 23 (2008) 3. https://doi. org/10.1109/TPWRD.2007.911124

\section{About the Authors}

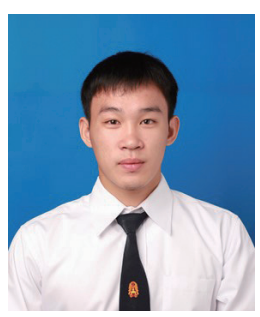

Panuwat Jamroen is a B. Eng. degree student in the Department of Electrical Engineering at King Mongkut's Institute of Technology Ladkrabang (KMITL), Thailand. His research interests are in high-voltage engineering applications. (60010779@kmitl.ac.th)

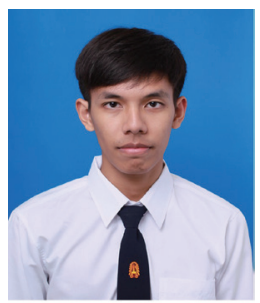

Poom Yoosorn is a B.Eng. degree student in the Department of Electrical Engineering at King Mongkut's Institute of Technology Ladkrabang (KMITL), Thailand. His research interests are in high-voltage engineering applications. (60010779@kmitl.ac.th)

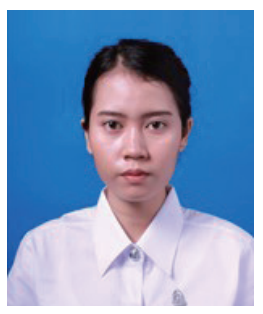

Suthasinee Waengsothorn is a B.Eng. degree student in the Department of Electrical Engineering at King Mongkut's Institute of Technology (KMITL), Thailand. Her research interests are in high-voltage engineering applications. (60010779@kmitl.ac.th)

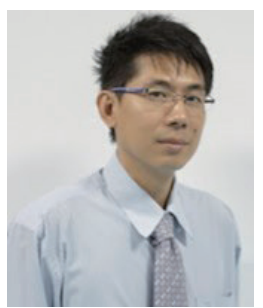

Peerawut Yutthagowith received his B.Eng. and M.Eng. degrees from Chulalongkorn University, Thailand, in 1998 and 2001, respectively, and his Ph.D. degree from Doshisha University, Japan, in 2010. Since 2007, he has been at King Mongkut's Institute of Technology Ladkrabang. His research interests are in high-voltage engineering applications and sensors. (peerawut.yu@kmitl.ac.th) 